\section{Reasons for non-timely completion of the routine infant immunization schedule by children in rural South West Uganda}

Many Ugandan children still die of vaccine-preventable diseases like pneumococcal pneumonia, rotavirus diarrhea and measles. ${ }^{1}$ Fewer children in low-income countries like Uganda complete their routine infant immunization schedule compared to those in high-income countries, e.g., only 52\% in Uganda by age 1 year compared to $90 \%$ in Canada by age 2 years..$^{2-5}$ An unpublished study in Kyabugimbi subcounty found that only $60 \%$ had received measles immunization by age one.

The purpose of this study was to explore the reasons why children in Kyabugimbi subcounty, Uganda, do not complete the infant immunization schedule by their first birthday.

\section{METHODS}

A cross-sectional population survey was conducted in one parish in Kyabugimbi subcounty in Bushenyi District, about 300 km southwest of the Ugandan capital, Kampala. This parish was purposively chosen as it lies farthest from the local health centre and is the most hard to reach. Kyabugimbi subcounty is typically rural with a hilly terrain and poor means of communication.

Using a structured interviewer-administered questionnaire in December 2014, adult caregivers of all children aged 12-23 months who resided in Bugara parish, as identified by the local Village Health Teams, were interviewed in their homes. No incentives were offered to participants. Collected data included child and caregiver biographical data, the child's immunization history, immunization card data, and the family's socio-demographic characteristics. In cases where the child's immunization card was not available, the child's caregiver was asked to recall this information using prompts. Caregivers of children with incomplete immunization information were requested to give reasons for the non-completion of immunization schedule. Responses were checked against an 11-item pre-coded list of reasons, such as availability of vaccine, incorrect information, or conflicting priorities.

Data were analyzed using STATA 11.0 (StataCorp); the percentage of children not fully immunized was calculated and the frequencies of the reasons for not completing the immunization schedule were determined. Ethical approval was obtained from the Institutional Review Committee of Mbarara University of Science and Technology (MUST) and written consent was obtained before each interview. The study was funded through a grant from MicroResearch (MR 13M MUS 01).

\section{RESULTS}

Of 73 eligible caregivers, 62 consented to participate; 11 were away and not available during the time of the interviews. The median caregiver age was 25 (22-31) years; all were females, 92\% were married, 73\% had primary education, 91\% were Christian faith and $90 \%$ were self-sufficient farmers. Of their eligible children ( $n=62), 56 \%$ were males, the median age was 17 (15-20) months,
90\% lived with both parents and $84 \%$ had been born at a health facility. All but 2 (3\%) had their immunization cards as a source of information. Only 39/62 (63\%) were up to date with their immunizations, 23 (37\%) were partially immunized; none were completely un-immunized. Only $37 \%(14 / 38)$ of the 12 - to 18 -month olds and $38 \%(8 / 21)$ of the 19 - to 23 -month olds were fully immunized. The most common reasons for incomplete immunization were no availability, e.g., stock out for 12 of 23 (52\%), followed by baby was born away from a health facility so missed initial vaccines at birth (7 of $23 ; 30 \%)$, then incorrect contra-indications (5 of 23; 22\%). Neither previous negative experiences with immunizers nor conflicting priorities were common reasons, each occurring in only 2 interviews (4.3\%). The missed vaccines included OPV-1, 65\%; measles vaccine, 26\%; OPV-3, 17\%; Pentavalent 3, 13\% and BCG, 4\%.

\section{CONCLUSIONS AND RECOMMENDATIONS}

Among the families interviewed, about one third of the children ages 12-23 months in the Kyabugimbi subcounty parish were only partially immunized. Lack of supply of the vaccine at immunization clinics and the baby's delivery site being away from a health centre were major influences on non-timely immunization completion. The Health Ministry and health workers may be able to improve timely immunization completion by addressing stock shortages. As delivering a baby away from a health centre also influenced timely completion, Village Health Teams in particular and the health care system in general need to better support mothers who have delivered in their village to start the infant immunization program on time and on schedule.

\section{Barnabas Atwiine, ${ }^{1}$ Aloysius Rukundo, ${ }^{2}$ Batume Elias, ${ }^{3}$} Noni E. MacDonald ${ }^{4,5}$

1. Department of Paediatrics and Child Health, Mbarara University of Science and Technology, Mbarara, Uganda

2. Department of Educational Foundation and Psychology, Mbarara University of Science and Technology, Mbarara, Uganda

3. Department of Nursing, Kampala International University Teaching Hospital, Bushenyi, Uganda

4. Department of Paediatrics, Dalhousie University, Halifax, NS

E-mail: noni.macdonald@dal.ca

5. MicroResearch Canada, Halifax, NS

doi: $10.17269 /$ CJPH.106.5393

\section{REFERENCES}

1. Chepkemoi ML, Karanja S, Kombich J. Immunization coverage and its determinants among children aged 12 - 23 months in a peri-urban area of Kenya. Pan Afr Med J 2013;14:3. doi: 10.11604/pamj.2013.14.3.2181.ISSN 1937-8688.

2. Government of Canada. Vaccine Coverage in Canadian Children: Highlights from the 2013 Childhood National Immunization Coverage Survey (cNICS), 2014. Available at: http://healthycanadians.gc.ca/publications/healthyliving-vie-saine/immunization-coverage-children-2013-couverture-vaccinaleenfants/index-eng.php (Accessed November 20, 2015).

3. Uganda Bureau of Statistics 2011. Uganda Demographic and Health Survey. Kampala, Uganda, 2012.

4. United Nations International Children's Emergency Fund. The State of the World's Children Report, 2014. New York: United Nations International Children's Emergency Fund, 2015.

5. World Health Organization. Global Immunization Data, Geneva, Switzerland: WHO, 2014. Available at: http://www.who.int/immunization/monitoring_ surveillance/global_immunization_data.pdf (Accessed November 20, 2015). 